\title{
Building the Chronology of \\ Early Chinese History
}

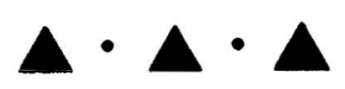

YUN KUEN LEE

IN THE STUDY OF THE PAST, CHRONOLOGY is one of the most important questions to learned individuals as well as to the general public. "How old is it?" is a legitimate question that every curious individual would ask about the past. When the answer is related to the age of an early culture, particularly to that past culture being regarded as the heritage of a specific human group, it might evoke sentiment from the audience. For historians and archaeologists, the answer to the question would have implications on the rate of change and evolution. China is one of the few pristine civilizations in the entire world. Firm dates of early Chinese civilization would, to a certain extent, facilitate the comparison between the processes of Chinese civilization and the other civilizations of the world. Nevertheless, the dates of early Chinese civilization have been debated for more than two millennia with no agreement.

The Xia-Shang-Zhou Chronology Project was designed to build a credible chronology of early China for the general public and the academic community starting from the first dynasty. The project was commissioned by the Chinese government in 1996. It employed a multidisciplinary group of 200 specialists in history, astronomy, archaeology, and radiocarbon dating who collaborated to solve the chronological puzzle of early Chinese history. After four and a half years of intense work, a new chronological table of early China, starting from 2070 в.C., was disseminated in November 2000 . The project immediately drew criticism from the news media (Eckholm 2000; Gilley and Zhou 2000) and circles of early Chinese studies experts in the Western world. This paper has two goals: to demonstrate how the project integrated different provenances of knowledge for the study of absolute dates; and to discuss the main debates around the project. These issues have general applicability to the study of other early civilizations.

One of the major criticisms of the project is that it was clearly motivated by a new wave of nationalism in China. However, study of the past has an intrinsic relationship with contemporary politics all over the world. Nationalistic-inspired studies of the past are not necessarily biased. I cannot find any indication that the chronology project ever tried to push back the dates of early Chinese civilization;

Yun Kuen Lee is an assistant professor in the Department of Anthropology at Harvard University, Cambridge, Massachusetts. 
all of the proposed dates have some reasonable supporting evidence, although the evidence is not always strong.

A more controversial issue is that the chronology project reinforces the notion that archaeology is a tool of historiography. The agenda of archaeology in China is set by history; and archaeological work that can answer historical questions is privileged. Archaeology in China does not have an independent epistemology that suits its unique characteristics. Thus, archaeological reconstruction of the past is based on a vision derived from history. The chronology project preserves the unilinear historical perspective of early China emanating from the documentary record, regardless that recent archaeology has indicated a more complex and multilinear developmental trajectory.

Another area of controversy is the compatibility of historical and archaeological dates. Historical and archaeological dates are two completely different types of knowledge. Historical dates extracted from documentary records often contain exact notations of time. On the contrary, archaeological dates are at best close approximations of time. To be more specific, all of the absolute dating methods used in archaeology are statistical estimations coded with margins of error of at least a few to hundreds and thousands of years. How to fuse the archaeological dates with historical dates is a challenge to all chronological studies of early civilization. The recent innovations in radiometric dating technology, coupled with creative strategies, enabled the chronology project to make some significant achievements in this area. The incompatibility of these two types of dates, however, remains.

Overall, the project systematically made use of the available data in different fields to reconstruct the chronology of early China. The collaboration among a large number of specialists from different disciplines enabled the project to achieve something that is impossible for an individual alone to achieve. In addition, some key information and research methods have only been available in the last few decades. The project's claim that the dates are the best dates given the presently available data is justifiable. It has definitely generated a chronological table that is more reliable than the previous chronological studies. However, there are areas that are controversial and a new round of debate has already started.

\section{BACKGROUND}

Shiji (Historical records) provided the basic structure or skeleton of the chronology of early Chinese history in use today. The book was compiled by Sima Qian, the Grand Historian of the royal court of the Han Dynasty at the end of the second century B.C. It documents the history of China from the days of the mythical culture heroes and sage rulers, to the three pre-imperial dynasties (Xia, Shang, and Zhou), and down to the author's own time. Starting from 841 B.C., the first year of the Gonghe reign of the Western Zhou period, Sima Qian compiled an absolute chronological table that systematically chronicled the events of twelve contemporary states (Kametaro 1974:227-266). Before that year, Sima Qian admitted that he was unable to reconstruct the exact chronology because of the inadequacy of material and could provide, therefore, only a list of kings for the rest of the Three Dynasties. Other historic sources claimed to provide the lengths of some reigns or the total length of each of the three dynasties, but they were 
often contradictory. Perhaps this was the reason why Sima Qian did not attempt to trace the chronology back any further. It did not stop the students of early Chinese study from trying to solve this chronological puzzle. However, studies based on the classical texts (classical texts in this paper refer to the documentation written in the Han and pre-Han periods) could not reach agreement. For example, the Zhou conquest of Shang was one of the most important historical events during this time period because it signaled the end of one dynasty and the beginning of another. A recent survey of the literature reveals that at least 44 different dates, from 1130 to 1018 B.C. (Beijing Normal University 1997), a span of 112 years, have been proposed. This crucial issue remains unresolved.

In 1996, the Chinese government commissioned the Xia-Shang-Zhou Chronology Project to generate credible dates for the Three Dynasties. The project was the brainchild of Song Jian, a senior official who oversaw scientific research policy in China. After a visit to Egypt, Song thought that a more accurate chronology for early Chinese civilization was desirable (Song 1999:21-22). He mustered enough support from a number of ministers in the Chinese government and succeeded in persuading the other council members to include the project in the government's ninth Five-Year Plan. A special committee headed by Li Xueqin, the then director of the Institute of History, Chinese Academy of Social Sciences, was formed; and a total of some 200 specialists in history, astronomy, archaeology, and radiometric dating were assembled. Unlike previous individual attempts to generate a chronology, this project did not rely solely on the textual sources, but systematic, interdisciplinary approaches were employed (Bulletin 69). ${ }^{1}$ The project examined the authenticity of chronological entries in the documentary records, used computerized retrocalculation to fix the dates of astronomical events documented in the classical texts, and extracted archaeological materials for radiometric dating. Specialists from different fields carried out their studies simultaneously and independent of each other (Bulletin 41, 51, 57). The results from different lines of investigation were compared and integrated at the close of the project. The final results were announced in Beijing on November 9, 2000. A chronological table that fills in the key gaps in the ancient records of China's earliest kings and dynasties for the Three Dynasties was disseminated (Table 1).

It is clear in Table 1 that there are differences in the precision level for different historical periods. For the Western Zhou and late Shang Dynasties, exact reign years are given to most of the kings. For the remote past of early Shang and Xia Dynasties, only rough estimations are given. These differences are attributed to the types and amount of data available for chronological study of different historical periods. The more remote the time, the more difficult to fix exact dates. During the news release, Li Xueqin maintained that these are the best dates given the presently available data.

\section{THE POLITICS OF THE STUDY OF THE PAST}

The government background of the Xia-Shang-Zhou Chronology Project soon invited criticism for its political motives (Chen Xingcan and Liu 2001). The Chinese government in the past had a reputation of high-handedly limiting the interpretive framework that humanities and social science scholars could use, and it did not hesitate to bend history to serve its present political goals (Tong 1995). 
Table i. Chronology of Early Chinese Dynasties

\begin{tabular}{llc}
\hline DYNASTY & \multicolumn{1}{c}{ KING } & CALENDAR DATES (B.C.) \\
\hline Xia & 17 kings & $2070-1600$ \\
Early Shang & 19 kings & $1600-1300$ \\
Late Shang & Pangeng, Xiaoxin, Xiaoyi & $1300-1251$ \\
& Wuding & $1250-1192$ \\
& Zugeng, Zujia, Linxin, Kangding & $1191-1148$ \\
& Wuyi & $1147-1131$ \\
& Wending & $1112-1102$ \\
& Diyi & $1101-1076$ \\
Wixin & $1075-1046$ \\
Western Zhou & Wuwang & $1046-1043$ \\
& Chengwang & $1042-1021$ \\
& Kangwang & $1020-996$ \\
& Zhaowang & $995-977$ \\
& Muwang & $976-922$ \\
& Gongwang & $922-900$ \\
& Yiwang & $899-892$ \\
& Xiaowang & $891-886$ \\
& Yiwang & $885-878$ \\
& Liwang & $877-841$ \\
Gonghe & $841-828$ \\
& Xuanwang & $827-782$ \\
& Youwang & $781-771$ \\
\hline
\end{tabular}

Source: Xia-Shang-Zhou 2000:86-88.

Song Jian, in a booklet on the chronology project, Chaoyue Yigu Zouchu Mimang: Huhuan Xia Shang Zhou Duandai Gongcheng (Overcoming skepticism, leaving perplexity behind: The call for the Xia-Shang-Zhou Chronology Project), makes it clear that his initial proposition for the project was motivated by nationalism. Under the section heading "An urgent need of the society," he admitted he was embarrassed on a 1995 trip to Egypt after seeing that the Egyptians had built a highly precise absolute chronology from the Third Dynasty (2750 B.C.). The Chinese were far behind in their own chronological study of their own early civilization (Song 1999:21-22). In another passage of the same book, Song maintains that in order to nurture the citizens' patriotic attitude, they should be encouraged to read history (Song 1999:4). As a consequence, the objectiveness of the chronology project was highly scrutinized by scholarly circles all over the world, including the Chinese (Chen Xingcan and Liu 2001).

Study of the past has been indelibly entwined with politics in all parts of the world (Meskell 1998); China is not alone. It is particularly true for archaeology because archaeology is institutionalized only when it becomes politically useful. After investigating the development of archaeology in Europe, Diaz-Andreu and Champion (1996) conclude that the appearance of nationalism stimulated the very creation of archaeology as a science, and informed not only the organization of archaeological knowledge but also its infrastructure. For one thing, archaeology yields material remains that appeal to the general public and are able to evoke emotion. In creating a nation in modern times, it is essential to formulate an ideology that assures national pride and justifies the nation's ethnic, racial, linguistic, 
religious, and cultural biases (Diaz-Andreu and Champion 1996; Özdoĝan 1998). The study of the past is such a practical tool in the search for the roots of a nation. Therefore, the disciplines of history and archaeology closely identified with state policy and all too readily became a distorted field of study that bent and ignored rules of evidence to promote the glory of the ethnic group in command (Kohl and Fawcett 1995).

Nevertheless, the intrinsic relationship between the study of the past and nationalism does not necessarily imply that the study of the past is inherently corrupted; it might have a positive effect. Certainly it is easier for scholarly projects with nationalistic implication to get government and sometimes private funding. Nevertheless, ethnically inspired studies of the past might stimulate research into the development of specific cultural traditions (Kohl and Fawcett 1995). After reviewing the long historical relationship between nationalism and archaeology in modern Europe, Trigger (1995) points out that under the influence of nationalism many archaeologists concentrated on documenting and interpreting the archaeological record of specific peoples. This new focus often led to more detailed description of material remains and encouraged archaeologists to trace spatial variations more systematically than they had done previously.

After realizing the unavoidable relationship between politics and study of the past, there is no reason that we should denounce the Xia-Shang-Zhou Chronology Project simply because it is politically and nationalistically motivated and was funded by the government. Chronology itself is a neutral question that does not have natural implications by itself, although how the chronology would be used for political manipulation is a different issue. The important question that we should ask is if the scientists of the project were able to maintain scientific rigor and determine the limits of the available data. Put another way, are they reconstructing the chronology of the Three Dynasties with reasonable confidence from the record? This is a complex question that I am going to discuss throughout the next few sections. In general, political interference in academic pursuits has become increasingly infrequent in the last two decades in China. My personal observation on the Xia-Shang-Zhou Chronological Project is that governmental influence on the project was administrative rather than ideological.

\section{HISTORY AND ARCHAEOLOGY OF THE THREE DYNASTIES}

History and archaeology, although both study the past, are two different disciplines with radically different provenances. History is capable of high-level resolution that can focus on individuals, dates, locations, and events of the past. Archaeology in contrast is strong in the recovery of long-term general patterns. The dependence on archaeological means to solve historical problems is inevitably a constrained strategy. In the archaeology of the Three Dynasties, it is only in very rare and lucky occasions that archaeologists can achieve the degree of resolution common in history. For example, the excavation of the grave of Fuhao-a consort of King Wuding of the late Shang Dynasty-enabled archaeologists to address the questions of an individual actor of the past, who is first seen in the oracle bone inscriptions (Zhongguo Shehui Kexueyuan Kaogu Yanjiusuo 1980). Examples like this are, nonetheless, atypical in archaeology.

If archaeology and history are used properly together, they complement each 
other's silences and fill the gaps in our knowledge of the past. On the one hand, some critical questions, for instance, specific dynastic sequences and key political relationships, can be addressed only through the study of documentary data. On the other hand, archaeology, particularly anthropological archaeology, allows us to expand narrow historical interpretations into fuller explanations of key transformations. Moreover, archaeological data can provide an independent line of evidence to ferret out biases in the documentary record (Stark and Allen 1998). These two classes of data are incommensurate, and it requires penetrating insight and sensitivity to use them together in a way to produce constructs of the past richer than can be achieved with either body of evidence alone (Wright 1998).

In reality, there often exists a tension between history and archaeology in the study of the historical period. Textual data and analyses are regularly privileged. The archaeological questions are determined by the historic vision of the past (Thurston 1997). Storey points out that in the study of classical Roman society, archaeology is treated as the "handmaid of history" (Storey 1999).

The Chinese historical texts depict Xia, Shang, and Zhou as three powerful early hegemonic states distributed along the middle reaches of the Yellow River during the second and the first millennia в.c. They are often referred to collectively as the era of the Three Dynasties in Chinese history. This does not mean that they were the only states in China at this time. Classical literature, bronze and oracle bone inscriptions, and archaeology testify that there were probably dozens, if not hundreds, of political entities dotting the terrain during the Three Dynasties era (Chang 1986:307). Nevertheless, the bulk of the written records on early China concern only these three early states, and were mostly written by their own historians.

It is not uncommon that early writers used history to express their own view of the past. Starting from the time of Confucius, the Three Dynasties were seen as the headwaters of Chinese civilization. Confucian philosophy maintains that particular individual behavior may bring subscribed consequence. For instance, in the writing of Shiji, the successions of Xia, Shang, and Zhou are said to be indications of the shift of the center of morality and where the Mandate of Heaven was lodged. When Jie, the last king of Xia, failed to uphold high moral standards, Tang of the Shang group seized the heavenly mandate from him (Kametaro 1974:47-48). The Shang group dominated China until Dixin, its thirty-first king, wallowed in vicious and degrading behavior, and lost the mandate to King Wenwang of Zhou (Kametaro 1974:55-57). This linear succession of three hereditary dynasties, alleged by Sarah Allan, was likely a creation of the Zhou people to support a theory of dynastic cycles (Allan 1984).

It is no secret that the primary role of archaeology in Chinese scholarship is to verify classical documents and supplement history (zhengjing bushi). Nonetheless, there are two different emphases of this approach to the archaeology of the Three Dynasties. The first emphasis is on the supplementary side, represented by the works of Chang Kwang-chih (1986) and Su Bingqi (1999). In light of recent archaeological findings, there is increasing evidence that there were highly complex cultures contemporary with the Three Dynasties located outside of the middle reaches of the Yellow River Valley. Chang and Su independently put forth the interaction sphere and the mantian xingdou (literally a starry sky) models, respectively. Both models emphasize the multiple origins of Chinese civilization and 
the interaction of various contemporary complex societies during the formative period of civilization. These models do not contradict historical documentation because early records have pointed out the great number of political entities contemporary with the Three Dynasties. Yet, this approach gives us a fuller and richer account of the past in contrast to unilinear history.

The second emphasis is on the verification side, represented by Zou Heng (1998a). It concentrates on seeking one-to-one correspondences between the historical and archaeological records. Since early history concentrates on the discrete succession and distribution of dynasties, polities, and ethnic groups, it is important to define the spatial and temporal framework of culture history in archaeology (Falkenhausen 1993). These archaeological units can then be equated to specific polities and ethnic groups (Allard 1998). This kind of research method of pigeon-holing archaeological finds into a historiographically based scheme prompts a series of studies on the identification of the capital sites of the early kings (e.g., An 1961; Cai and Luo 1988; Chen 2000; Li, Li, and Shi 1999; Zou $1998 b$ ). The chronology project preserved the unilinear model of early Chinese civilization emanating from the early written documents. It charged archaeology to recover datable materials from sites corresponding to the ancient capitals. Consequently, it allowed written history to determine the scope and content of archaeology.

I have to stress that modern Chinese historiographers do not automatically accept what had been written in the early documentary records. In the last few centuries, Chinese historians went through a period of introspection. They scrutinized the authenticity and historicity of the classical texts. They challenged the traditional, particularly the Confucian, perspective of the history of the Three Dynasties. It was realized that there was no value-free documentation; a critical perspective is a prerequisite when using written data. Documentary records should be evaluated for methodological biases, cultural context, and the historical circumstances of their production (Junker 1998). In the 1920s, Gu Jiegang-the founder of the skeptical school of early Chinese history (yigupai) - pointed out the curious fact that the later the time, the longer the legendary period of early history. The oldest culture hero that the Western Zhou people knew was Yu, the founder of the Xia Dynasty; Confucius of the Spring and Autumn era knew Yao and Shun, the sage rulers preceding Yu; People of the Warring States knew about the older kings like Huangdi and Shennong; and so forth. He thus proposed the hypothesis that early Chinese history is a tale told and retold for generations, during which new elements were added to the front end ( $\mathrm{Gu} 1982)$. Classical records of the Xia include many obvious legends and myths; for example, the claim that ten suns rose simultaneously during the reign of King Yinjia (Fang and Wang 1981:13). Much of our knowledge of the Xia Dynasty stems from retrospective writing centuries later. The actual existence of Xia was openly questioned by $\mathrm{Gu}$ Jiegang and others ( $\mathrm{Gu}$ and Tong 1982). However, it is possible that authentic historical facts can be isolated from the inaccurate and fabricated elements through painstaking triangulation of the passages in question with other classical writing as well as inscriptions on bronze. The skeptical school went on to edit and publish seven volumes of Gushibian (Debating ancient history), which systematically weeded out many of the unauthentic entries of early Chinese history from the classical documents. 


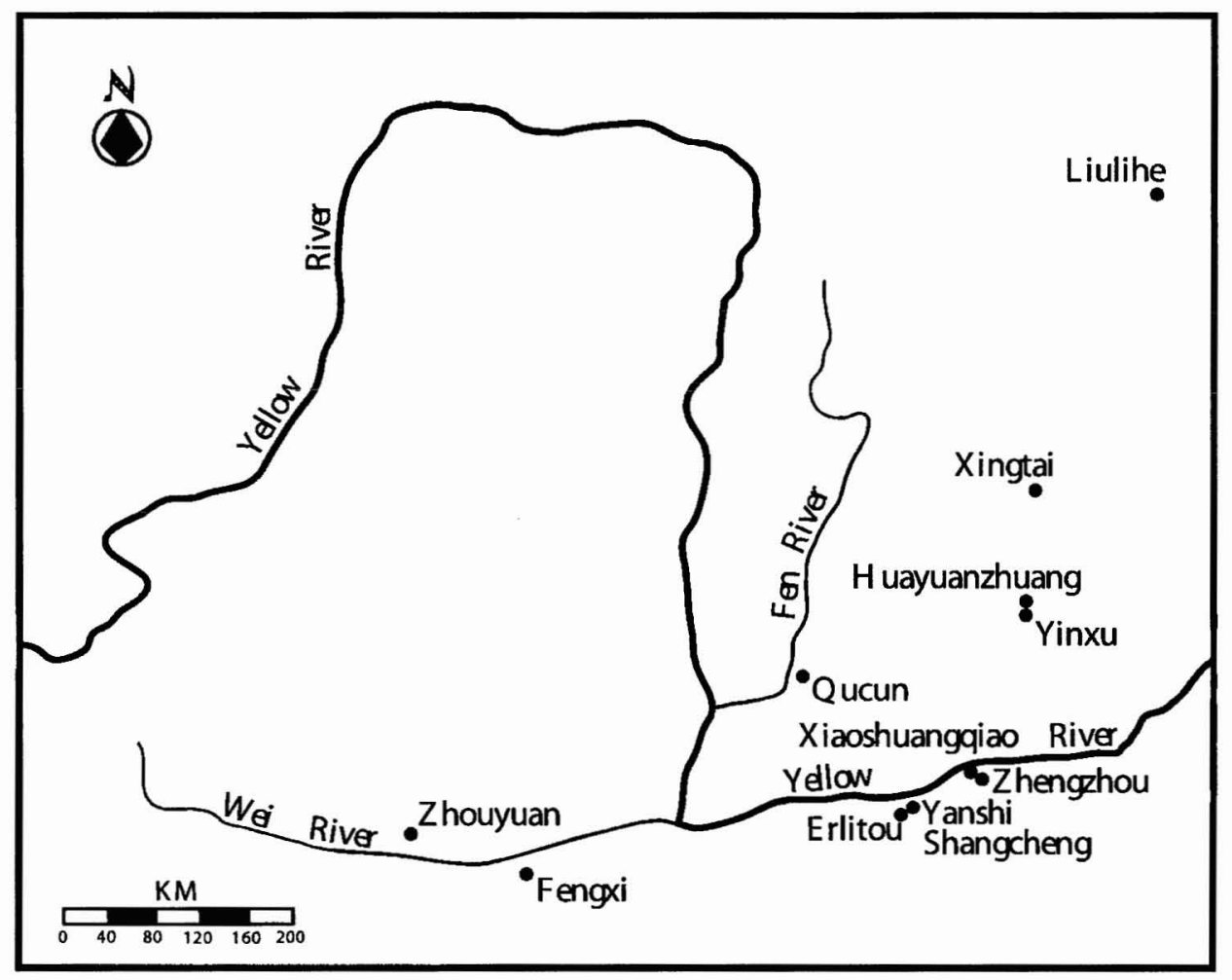

Fig. 1. Three Dynasties archaeological sites.

More than seven decades have since passed, and contemporary Chinese scholars are more positive than ever on the historicity of early Chinese documents. Today, the majority of Chinese scholars believe that they have weeded out most of the nonhistorical entries in the early texts. For instance, Li Xueqin systematically screened the entries concerning the Xia in Guben Zhushu Jinian (Bamboo annals original text) and has convincingly argued the historicity of a significant number of these entries (Li Xueqin 1997:49-54). During the International Seminar of Xia Culture held in 1990 at the University of California, Los Angeles, the Western scholars were about equally split on the question of whether the Xia Dynasty actually existed, while the Chinese participants were in unanimous agreement that it did (Du 1990).

The belief in the historicity of Xia does not have much authority without the empirical documentation provided by archaeology. In 1959, inspired by the textual records that western Henan and southwestern Shanxi were described as the homeland of the Xia people, $\mathrm{Xu}$ Xusheng organized an archaeological survey in search of the ruins of the Xia Dynasty ( $\mathrm{Xu}$ 1959). His field expedition soon revealed that the Erlitou site at Yanshi (Fig. 1) was a rich and expansive site of about 400 hectares in total area (Zhongguo Shehui Kexueyuan Kaogu Yanjiusuo 1999:6). Subsequent excavations indicate that the site has multicultural components showing characteristics of the Yangshao, Miaodigou II, Erligang, and Han cultures. Nevertheless, the major deposit sandwiched in between the Miaodigou 
II layer and Erligang layer was a distinct new culture characterized by roundbottomed and tripod ceramic vessels (Zhongguo Shehui Kexueyuan Kaogu Yanjiusuo Luoyang Fajuedui 1961, 1965). This specific assemblage was later coined as the Erlitou culture. Traditionally, the Erlitou cultural deposit at the Erlitou site is partitioned into four successive developmental phases, from the earliest Phase I to the latest Phase IV, as evident in the stratigraphy of the site (Zhongguo Shehui Kexueyuan Kaogu Yanjiusuo 1999:19-20). Sites yielding material remains similar to those recovered from Erlitou are distributed widely in the western Henan and southwestern Shanxi region, and are grouped under the rubric of Erlitou culture. The initial coring of the Erlitou site with a Luoyang spade (an augering device used by the local tomb looters) in 1959 yielded remains of rammed earth. Excavation at Erlitou in the fall of 1961 revealed for the first time Phase III, an extensive rammed earth platform enclosed by earthen walls. The enclosure measured more than 1 hectare in area (Zhongguo Shehui Kexueyuan Kaogu Yanjiusuo Erlitou Gongzuodui 1974). Large rammed earth features were either used as foundations for elite residences or public ceremonial buildings in later periods. It was quite natural for archaeologists to interpret the earthen features as a palacetemple foundation. In addition, bronze wine vessels and hardstone and jade artifacts that were used in royal ritual ceremonies during the Shang and Zhou times, and a second rammed earth feature were also found among the Phase III deposits (Zhongguo Shehui Kexueyuan Kaogu Yanjiusuo 1999:151-156). It is evident that during Phase III, Erlitou had developed into a highly organized and complex urban center that sustained considerable administrative and ceremonial capacities. However, the key question among Chinese archaeologists-which phases of the Erlitou culture were that of the Xia period, and which phases were that of the Shang period-has become a perennial debating agenda for the past quarter century. Put another way, was the urban center seen in Phase III at Erlitou the royal ruin of the Xia or that of the Shang?

It is beyond the scope of this paper to unravel all the arguments of this debate (see Thorp 1991 for details). A great number of authors have published their opinions on the issue, nevertheless, they support one of the following major points of view: (1) Zou Heng (1979) argued that all four phases of Erlitou were Xia culture; (2) Sun Hua (1980) argued that Erlitou Phases I to III were Xia culture, while Phase IV was Shang culture; (3) Yin Weizhang (1978) advocated that Erlitou Phases I and II were Xia culture, and Phases III and IV were Shang culture; and finally (4) Zheng Guang (1988) maintained that only Phase I was Xia culture, and the other phases were Shang culture.

This debate is to a large extent attributable to the mixed signals from the classic documents. The general area of Yanshi has been pointed out by the different classical documents as the location of the capital of the Xia and at the same time, it was where Bo (or Xibo, literally western Bo), the first capital of Shang dynasty, was located (for a summary of the classic documents, see Zhongguo Shehui Kexueyuan Kaogu Yanjiusuo 1999:392). Archaeologists, therefore, either line up the administrative center of Erlitou Phase III with the Xia capital or with Bo, the first Shang capital.

The momentum gradually shifted to support the first and particularly the second schools in light of new archaeological findings at Shixianggou in Yanshi. In 1983, a large fortified walled site enclosing an area of slightly less than 200 hec- 
tares was found just $6 \mathrm{~km}$ northeast of Erlitou (Zhongguo Shehui Kexueyuan Kaogu Yanjiusuo Luoyang Han Wei Gucheng Gongzuodui 1984). The walled enclosure was partitioned into two parts, a smaller enclosure was encircled by a larger one. Inside the smaller enclosure, a cluster of about ten large rammed earth platforms was revealed through archaeological coring and excavation (Wang Xuerong 1997; Zhongguo Shehui Kexueyuan Kaogu Yanjiusuo Henan Dier Gongzuodui 1984, 1988, 1999). Both radiocarbon dating and ceramic seriation indicate that when the Shixianggou site (known as Yanshi Shangcheng) rose to become a major urban center, the Erlitou site declined and was soon abandoned. In addition, the ceramic assemblage yielded from Yanshi Shangcheng was predominantly that of the typical Erligang style, and was diagnostically different from Erlitou ware. It is now commonly accepted among archaeologists that the Erligang culture represents the material remains of the Shang people. The seemingly conflicting signals in the classical texts no longer conflict if we interpret the Phase III remains at Erlitou as the ruins of the Xia, while Yanshi Shangcheng was that of the Shang. Although the original authors of the third and the fourth schools still maintain their arguments, several of their major supporters have defected to support the first and second school (Gao et al. 1999; Wang Wei 2000; Zhongguo Shehui Kexueyuan Kaogu Yanjiusuo 1999:394). The official position of the chronology project is that all four phases of Erlitou culture were that of the Xia people.

The above discussion of the processes of the historical and archaeological identification of Xia Dynasty is necessary to exemplify the intellectual evolution in the study of the early historical period. The skeptical school was meant to deconstruct a corrupted ancient history, and it succeeded. Nonauthentic texts and nonhistorical entries in the texts were systematically weeded out. In the next six or seven decades, Chinese scholars focused on the reconstruction of ancient history by using the remaining authentic sources. Other than textual records, inscriptional and archaeological data were also used in the reconstruction. When Xu Xusheng set out from Beijing to survey the region said to be the core activity area of the Xia people, his unambiguous goal was to use archaeological means to solve a historical question. In this regard, he had solved a huge historical puzzle since most of the Chinese scholars now agree that Erlitou was at one time the capital site of the Xia Dynasty. But the above discussion also indicates that archaeology in China does not have a logical and epistemological independence from history. The previous debate on Erlitou revolved around whether it was Bo or not. This is a historical question that archaeology can never provide conclusive evidence for, unless the excavation at Erlitou one day yields inscriptions. The debate also implicitly assumed that Xia was a state-level sociopolitical organization, therefore the Erlitou site was the capital site of a state polity. This assumption, I insist, must be tested. Here is where archaeology must develop its independence in epistemology from the tyranny of writing so that we can exploit its unique characteristics in the recovery of general patterns.

The perspective of anthropological archaeology can offer some suggestions on how we can better study the Erlitou culture. If Xia was a state (as the historical texts suggest), as an archaeological phenomenon, the sociopolitical complexity of Erlitou (both the type site and the other Erlitou culture sites) has to be systematically monitored. Ritual objects and sizable architectural features are important but 
insufficient to demonstrate that the site was the political center of a state. Different theories on state formation emphasize different variables. If the formation of social classes is important to the definition one subscribes to, the social stratification of Erlitou culture has to be examined. If decision-making is crucial to one's definition, settlement pattern data have to be collected and analyzed, and so forth. This kind of theory-laden systematic study is still in its infancy in China. I am currently involved in a collaborative project studying the settlement pattern around Erlitou and Yanshi Shangcheng in the lower Yi-Luo River Valley. Our aim is to monitor the development of the political economy in the study area through time. Until these kinds of studies have yielded the necessary information, we cannot confidently argue that Erlitou culture represents a state.

Regardless of the achievement of the skeptical school, study of the Three Dynasties has become increasingly conservative in recent years (Falkenhausen 1993). Although the skeptical approach had enabled the systematic examination on the historicity and authenticity of the documentary data, it did not rectify the source-side biases of the data. Therefore, the perspective of how to study the past is still dominated by written history, albeit an improved written history. The lack of an independent archaeological epistemology prevents archaeology from offering an alternate perspective of the past. Sun Hua (1999) correctly points out that by adhering closely to historical questions, Chinese archaeology has missed an opportunity to reconstruct a rich and thick texture of early China. The chronology project, which stressed the unilinear succession of the Three Dynasties, further compromised archaeology.

\section{RADIOCARBON DATING}

Archaeology itself does not provide absolute chronology. It is through the use of scientific dating methods on archaeological material that absolute dates can be derived. Nevertheless, historical dates and archaeological dates are not highly compatible.

The most commonly used scientific dating method in archaeology is the radiocarbon method. The chronology project used both the conventional and the accelerator mass spectrometric (AMS) methods for the derivation of ${ }^{14} \mathrm{C}$ dates. All radiocarbon laboratories quote the ${ }^{14} \mathrm{C}$ dates with margins of error (standard deviations) that are attributable to random and systematic processes. In practice, the vast majority of ${ }^{14} \mathrm{C}$ dates from archaeological remains of the second and first millennia B.C. derived in the past have margins of error greater than 60 years (Xia-Shang-Zhou 2000:113). This precision level of ${ }^{14} \mathrm{C}$ dating is of little value in resolving the arguments of the Three Dynasties' chronology. Recent innovations in radiocarbon dating and calibration, however, can greatly reduce the margin of error to a level at least marginally meaningful to the discussion of historical dates.

Given that radiocarbon decay is a random process, improvement in precision can be achieved by increasing the sample size and count time, though there are practical limits on both of these. In ideal situations, the margin of error in ${ }^{14} \mathrm{C}$ dates can be reduced to less than 20 years (Bowman 1990:40).

Wiggle-matching is a calibration procedure that can dramatically improve the precision when ${ }^{14} \mathrm{C}$ dates are converted to calendar dates. The calibration curves 
are not smooth progressions, but are full of short-term irregularities or wiggles (Stuiver et al. 1986, 1998; Vogel et al. 1986). At certain points a single radiocarbon result may correspond to several calendar dates, and thus significantly reduce the precision level. The wiggling feature of the calibration curve, however, can be used in a way that improves precision. If we have well-stratified samples, like a timber with countable tree-rings, we can extract samples from the log at fixed intervals, say every twenty years, for radiocarbon dating. A floating segment of a dating curve is derived. This floating segment can be fixed in calendar time by matching it to the master calibration curve (Buck et al. 1992; Christen and Litton 1995; Pearson 1986). It has been argued that a date of within \pm 5 years can be derived from a log recovered in a burial context by using the wiggle-matching technique (Kojo et al. 1994). Note that this error margin is not a standard deviation but a time range within which it is almost 100 percent certain that the actual date should fall. The wiggle-matching technique can be conducted heuristically with the naked eye. More and more radiocarbon workers, including the ${ }^{14} \mathrm{C}$ specialists of the chronology project, use a computer program called OxCal developed by Christopher Bronk Ramsey of Oxford University for wiggle-matching (Ramsey 1995, 1998). The program, disseminated through a web site, uses Bayesian statistics and the least-square method to execute the matching.

The advantage of Bayesian statistics in radiocarbon calibration is that information concerning stratigraphy or the depositional rate of the archaeological record can be incorporated into a hypothesis that reduces uncertainty and improves precision. The Bayes Theorem is an alternative view of statistics. It deals with subjective probabilities: the belief that one might hold about a particular event (Christen and Litton 1995; Dehling and van der Plicht 1993; Orton 1980:220). For a log with countable tree-rings recovered from an archaeological context, a sequence of high-precision radiocarbon determinations is derived for an interval of every twenty years. Each ${ }^{14} \mathrm{C}$ date might have a margin of error of 20 years. Given that we know there is a twenty-year difference of the actual calendar dates between two sequential samples, we can calculate a new probability-posterior probability-for each of the ${ }^{14} \mathrm{C}$ dates. This procedure has the effect of significantly improving the precision by reducing the age ranges of the dated events (Ramsey 1994). It is not an overstatement that the most archaeologically meaningful radiocarbon determinations arise when multiple dates are available from a number of contexts with well-stratified sequences; these dates contain both highquality archaeological and radiocarbon information (Buck et al. 1991).

The ${ }^{14} \mathrm{C}$ dating laboratories in China were behind the recent developments in the field (Bulletin 58) and could not meet the challenge of the Xia-Shang-Zhou Chronology Project. The precision levels of conventional and AMS laboratories were about \pm 80 and \pm 100 years, respectively. With governmental funding funneled to the chronology project, radiocarbon laboratories in Beijing underwent a considerable technological transformation. The improvement on the conventional installation is particularly notable.

After the technological transformation, the conventional laboratory of the Institute of Archaeology in Beijing has achieved a high level of precision and reliability (Qiu and Cai 1997, 1998). Although it has not reached the goal of reducing the error margin to 20 years, the results are consistently maintained around 35 years, thus reducing the error margin by more than half. Wiggle-matching of a 
series of well-stratified samples can significantly improve the precision of the calibrated calendar dates. In cases when timber logs with countable tree-rings were recovered from archaeological contexts, series of high precision ${ }^{14} \mathrm{C}$ dating and wiggle-matching produced highly precise results of \pm 8 years (there are two examples that yield \pm 8 years results: a $\log$ recovered from a abandoned well at Zhengzhou and a specimen of charcoal recovered from M8 at Qucun).

The AMS laboratory of Beijing University also has achieved a high level of precision and consistently produces dates of \pm 40 to \pm 50 years among the 200 tested samples. Seven samples were split and tested in Beijing and in the radiocarbon laboratory of the University of Toronto, one of the most reliable laboratories in the world, for the detection of systematic error (Bulletin 58,87 ). The results were encouraging in that six out of the seven samples yielded comparable dates within one standard deviation (Bulletin 77). However, the tests on oracle bones are disappointing in that about one-third of the dates seem to be systematically older than the expected dates by 200 to 400 years (Bulletin 90; Xia-Shang-Zhou $2000: 53)$. The reason for this is not yet clear, though a prevalent hypothesis is that the preservative and adhesive agents used on the oracle bones have contaminated the samples (Bulletin 87).

The chronology project witnessed for the first time in China radiocarbon specialists working hand-in-hand with archaeologists to pursue optimal sampling strategies for the derivation of high-quality calendar dates. Archaeologists and radiocarbon specialists used to have little rapport; they worked independently and seldom interacted with each other. However, the wiggle-matching procedure requires close cooperation. The archaeological information is crucial for the wigglematching procedure. In order to select the optimal samples in the first place, it is best for the ${ }^{14} \mathrm{C}$ specialists to work with archaeologists at an early stage to collect series of samples in well-stratified contexts. After the derivation and calibration of the ${ }^{14} \mathrm{C}$ dates, the radiocarbon workers have to consult the archaeologists for wiggle-matching strategy and interpretation of the results (Bulletin 22, 77). If the archaeological information is inaccurate or unavailable, high-precision calendar dates cannot be obtained (Bulletin 48). The chronology project has set a model for the cooperation of archaeologists and ${ }^{14} \mathrm{C}$ specialists, which may dramatically improve the precision of ${ }^{14} \mathrm{C}$ dating in the future.

The collaboration between radiocarbon specialists and archaeologists has already shown some exciting results. Only a portion of the ${ }^{14} \mathrm{C}$ dates of the chronology project has been published. These dates might have solved some important puzzles of Three Dynasties archaeology. One of these puzzles concerns the status of the recently discovered walled site in Anyang.

Archaeologists have been working in Yinxu at Anyang since 1928 (Li Chi 1977; Zhongguo Shehui Kexueyuan Kaogu Yanjiusuo 1994). It is the most thoroughly studied archaeological site in China. A combination of historical documentation, oracle bone inscription, and archaeology has firmly established the status of Yinxu as the last capital of the Shang Dynasty. However, it is still unclear if it was the "Yin" that King Pangeng moved to, as depicted in the classical documents. The predominant cultural remains at Yinxu are that of the period from King Wuding to King Dixin (the twenty-second to thirty-first kings). The cultural remains (i.e., Yinxu Phase I) corresponding to the time period of Kings Pangeng, Xiaoxin, and Xiaoyi (the nineteenth to twenty-first kings) are meager, 
small in scale, and low in status; they are no parallel to a royal capital (Tang Jigen 1993; Yang Xizhang 1981). Therefore, a growing number of scholars became increasingly skeptical about the status of Yinxu as the capital of King Pangeng (Peng and Xiao 1988). The discovery of a Shang walled site-Huayuanzhuangjust a few kilometers north of Yinxu in 1998 (Zhongguo Shehui Kexueyuan Kaogu Yanjiusuo Anygang Gongzuodui 1998) triggered some to argue that this newly discovered walled enclosure was the "Yin" that King Pangeng moved to, while Yinxu was a new capital that King Wuding moved to (Tang Jigen and Xu 1999). The competing hypothesis is that this newly discovered site was Xiang, where King Hetanjia (the thirteenth king) moved to (Wen 1998). High-precision radiocarbon dating can test these two hypotheses.

During the chronology project, seven Yinxu Phase I ${ }^{14} \mathrm{C}$ assays derived from Yinxu and Huayuanzhuang give a calendar range of 1370 to 1220 B.C. (all dates calibrated with the OxCal program), and these dates cluster around 1300 B.C. (Xia-Shang-Zhou 2000:51,71). On the other hand, eight Huayuanzhuang phase samples yielded a range of 1520 to 1325 B.C., and most of the dates cluster around 1400 в.C. (Xia-Shang-Zhou 2000:71). These dates support the hypothesis that Huayuanzhuang was the capital site of King Hetanjia instead of King Pangeng.

Another example of the significance of radiocarbon dating to the Three Dynasties discussion is the sequence of the rise and fall of Erlitou and Yanshi Shangcheng. The three Erlitou III samples give a calendar range of 1610 to 1555 B.C., and the four Erlitou IV samples give a range of 1564 to 1521 B.C. (Xia-ShangZhou 2000:77). Four Yanshi Shangcheng early Phase I dates range from 1600 to 1505 в.C., and six late Phase I dates range from 1565 to 1486 B.C. (Xia-ShangZhou 2000:67-68). These dates support the hypothesis that Erlitou and Yanshi Shangcheng were contemporaneous for some time. It seems that by the end of Erlitou III, Yanshi Shangcheng Phase I started to emerge, and this phase coexisted with most of the span of Erlitou Phase IV.

The project's technological investment greatly improved the precision of the radiocarbon laboratories at Beijing. Together with serial sampling strategies and the wiggle-matching method, radiocarbon dating is producing higher resolution calendrical dates. The newly derived dates not only help to solve some historical puzzles, they also have implications for the discussion of sociocultural evolution on a microlevel.

\section{PALAEOGRAPHY}

Other than classical documents, written records also include palaeographic material: the inscriptions on bronze objects and oracle bones. These are the archives of the Shang and Zhou dynasties, so they can be used as touchstones with which to gauge the authenticity of historical texts.

Bronzes in the Shang and Zhou periods were sumptuous goods used to symbolize the status of the elite class. They were often cast to commemorate important social and political events. Bronze artifacts have been continuously unearthed for the last two thousand years, yet the first systematic palaeographic study of these early bronzes dates back only to the eleventh century A.D. (Shaughnessy 1991:9). The study of bronzes has since grown into a strong scholarly tradition. To date, it is estimated that more than ten-thousand inscribed bronze objects 


\begin{tabular}{|l|l|l|l|l|l|l|l|l|l|l|l|l|}
\hline Tiangan & jia & yi & bing & ding & wu & ji & geng & xin & ren & gui & \multicolumn{4}{|l|}{} \\
\hline Dizhi & $z i$ & chou & Yin & mao & chen & si & wu & wei & shen & you & xu & hai \\
& & & & & & & & & & & & \\
\hline
\end{tabular}

Fig. 2. The ganzhi cycle.

have been collected and curated by museums, research institutes, and private collectors (Wang Zhongshu 1984). The contents of the bronze inscriptions are primarily political. A handful of the Zhou bronze inscriptions also bear the dates of important events, which are informative sources for chronology building. The dates on the bronze inscriptions may contain one or more of the four elements in calendrical notation: the day, the lunar phase, the month, and the year of reign.

The day is recorded according to the ganzhi system (Fig. 2). This is a sexagenary designation system comprised of ten tiangan (heavenly stems) and twelve dizhi (earthly branches). ${ }^{2}$ Assuming that this day designation system has been in use continuously since the beginning of Western Zhou, we might extrapolate back in time from a fixed historical day with a ganzhi designation and so determine the ganzhi designation of any other day (Shaughnessy 1991:136).

The lunar-phase notations include four primary terms - chuji (first auspiciousness), jishengpo (after the growing brightness), jiwang (after the full moon), and jisipo (after the dying brightness)-designating particular times within the lunar cycle (Shaughnessy 1991:146). There are competing theories on how the Zhou people designated these notations based on whether they were used to designate periods of lunar phases or were instead fixed days (Bulletin 29). The chronology project organized a systematic study of the late Western Zhou bronze inscriptions, and the study tentatively concluded that the terms were used to designate four phases of the lunation (Bulletin 52; Xia-Shang-Zhou 2000:36).

The third element of a bronze inscriptional date is the month. The Western Zhou calendar was a lunisolar one in which the moon's phase and seasonal changes were reconciled by expressing the twelve-month year by occasional use of an intercalary month. The difficulty in reconstructing the Western Zhou calendar is that it was unsystematic. Some important observations concerning the Western Zhou calendar have been made after a careful study of the several hundred astronomical entries in the classical texts (Xia-Shang-Zhou 2000:19). During the early Western Zhou Dynasty, the first day of the month was set at the first sighting of the new moon (the second or the third day of the month according to the modern lunar calendar). It was in the late Western Zhou that the first day had changed to the day before the first new moon sighting (viz. the first day of the month according to the modern lunar calendar). Another issue is the question of how the first month of the year was determined. It was found to have been fixed mostly at the month of the winter solstice; however, the following month was occasionally used as well (Bulletin 52). The intercalary month was placed at the year's end.

Finally, the year notation has its own problem. The year refers to a year in a given reign, though it seldom mentions the king by name (Shaughnessy $1991: 147)$. Therefore there is room for debate on which king is intended in a 
given inscription. A second problem is that there was no rigid rule as to when the "first year" of a reign was determined. The year when the old king died and the new king ascended to the throne and the following year were both used during the Western Zhou Dynasty (Xia-Shang-Zhou 2000:19).

Inscriptions containing all four elements of calendrical notations are most useful for building a chronology, but they are rare and consist of only sixty out of the ten thousand presently available inscriptions. Yet, they are valuable because they not only provide the date in year, month, and day, but also bear the lunar phase information. After the bronzes are assigned to their calendrical designations they can be tested using their own lunar-phase notations. Consequently, the assumption that the ganzhi cycle had not been interrupted since the beginning of the Western Zhou can be tested. This is not circular but hermeneutic reasoning because the hypothesized calendrical system would work only when all of these elements fit.

The value of lunar phase information for the building of the Western Zhou chronology is somewhat constrained because it is an astronomical event that happens so frequently. Nonetheless, the occasional documentation of infrequent astronomical events are the most useful information for anchoring the chronology. According to the Bamboo Annals, "[in] the first year of King Yiwang, the sun rose twice at Zheng" (Fang and Wang 1981:58). This entry has been interpreted as a solar eclipse shortly after sunrise. The Universal Law of Gravity developed by Newton allows for the mathematical prediction and retrocalculation of the orbital movement of celestial bodies to exquisite detail. The conditions have been set such that a solar eclipse occurred at sunrise and was visible at Zheng (located near the modern city of Xian). A calculation of all the solar eclipses occurring between 1000 B.C. and 877 B.C. indicates that the astronomical event in question must have happened on 21 April 899 B.C. (Bulletin 74). This date is supported by the inscriptions on the Shihu gui-vessel: "During the first year of the king, in the sixth month, after the full moon (jiwang), jiaxu day,..." (Xia-Shang-Zhou 2000:25). Typological studies have assigned this vessel to the reign of King Yiwang. If King Yiwang came to the throne in 899 B.c., the jiaxu day of the sixth month of that year was the nineteenth day of the month. Given that the full moon should have been observable on the fifteenth or sixteenth day of the month in the lunar calendar, the ascribed date is consistent with the lunar notation jiwang. With this result, 899 B.C. (the first year of King Yiwang) is identified by the chronology project as one of the seven critical datum points of the Western Zhou chronology.

The above example has demonstrated the essential quality of the building of the Western Zhou chronology. Datum dates are fixed through the systematic triangulation of different data. A noteworthy point is that the thorough investigation of these data requires expertise in several different fields and a number of skills that are almost impossible for any single individual to fully comprehend. It is only through the collaborative effort of specialists in different fields that such a high quality chronological scheme can be achieved.

Other than the bronzes, the inscriptional material also includes oracle bones. The oracle bones were first discovered in 1899 by a noted antiquarian who was ingesting ground bones as part of a prescription to treat his ailing health. We now know that the royal houses of the late Shang and early Zhou heated cattle scapu- 
lae and turtle plastrons to make cracks for divinatory purposes. Records were then inscribed on the bones to document the inquiries made and, sometimes, the answers given (see Keightley 1978).

Unlike the bronze inscriptions, oracle inscriptions contain only the day notations using the ganzhi system. It is more difficult to use the oracle bones for the reconstruction of an absolute chronology of the Shang Dynasty. Nevertheless, there are two sets of records that are particularly useful for chronological study of the late Shang Dynasty: the documentation of ritual cycles and that of the solar and lunar eclipses.

During the last few decades of the Shang Dynasty, oracle inscriptions documented that the Shang kings were involved in a ritual cycle based on the xun (ten-day weeks) of the ganzhi system that systematically offered five different sacrificial rites to past kings and queens. A full cycle needed approximately a Julian year to complete (Bulletin 54,64). These records are instrumental to the reconstruction of the reigns of Kings Diyi and Dixin, the last two kings of the Shang Dynasty.

A total of eleven entries of possible solar and lunar eclipses have been documented in the presently available corpus of oracle inscriptions (Bulletin 18, 28). The question of how to decipher some of them is still a matter for debate. Nevertheless, there is general agreement among palaeographers that the five entries of lunar eclipses in the Bin group oracle inscriptions are genuine observations. The Bin group is a group of oracle inscriptions that include approximately twenty-five diviners associated by the appearance of their names on the same bone, by the similar contents of their divinations, and by common pit provenance (Keightley 1978:31). They were active during the late Wuding and Zugeng reigns. Given the temporal duration essential for the Bin group, it is assumed that all five lunar eclipses should have been observable at Anyang within a period of no more than 60 years, though a span of 30 years is more reasonable. The astronomical calculation suggests that they could have occurred only between 1201 and 1181 B.C., a span of 30 years (Bulletin 47). These dates are important for the determination of the regnal years of King Wuding and King Zugeng.

\section{THE ZHOU CONQUEST OF THE SHANG}

If there is one single date that is the key in the chronology building of the Three Dynasties, it must be that of the Zhou conquest of the Shang. This date signified the end of one dynasty and the beginning of a new one. If it can be securely fixed, we can count forward and permute the regnal year of each of the Zhou kings. We can also count backward for the chronologies of the Shang and Xia. The classical texts give lively accounts of the military campaign, which I summarize as follows:

King Wuwang of the Zhou led an army of three hundred war chariots, three thousand "tiger warriors" plus troops sent by other allied states to a place called Muye, just south of Shang King Dixin's palace at Zhaoge. Dixin hastily recruited a large but disorganized army to the defense. In the clear and bright morning of the jiazi day, Wuwang made a solemn pledge and charged the chariots toward the Shang troops. After a brief skirmish, the Shang army turned their weapons on their own king, and Wuwang won a decisive military victory. Dixin retreated to his Deer Terrace pavilion and burned himself to death. 
That was how the Zhou seized the mandate from the Shang. We even know that the first skirmish of the Battle of Muye took place in the morning of a jiazi day, the first day of the ganzhi cycle. However, the most important information, the year, is missing. This has been a perennial issue for debate among students of early Chinese history for the last two millennia. In all, a total of at least 44 different dates have been proposed (Beijing Normal University 1997). The controversy is primarily attributable to the differential interpretation of the classical documents and understanding of the Zhou calendar. The earliest date is 1130 B.C. and the latest is 1018 B.C., a difference of 112 years. It is hopeless to attempt to solve this chronological puzzle by using the classics alone. The recent availability of other classes of information like archaeology and bronze inscriptions gives this old question new hope.

The strategy taken by the chronology project is first to shorten the range of possible dates by archaeological means, and then to use the astronomical events documented in the text to determine the most likely date. There are no datable material remains directly related to the conquest. The battlefield of Muye has not been found. The charred remains of the Deer Terrace pavilion have yet to be identified. Nevertheless, there are a number of historical events that occurred before and after the conquest, which have yielded datable archaeological materials. They can then be used to determine the upper and lower limits of the conquest date.

The most complete sequence of events in relation to the conquest is found in Fengxi (Zhongguo Shehui Kexueyuan Kaogu Yanjiusuo Fenghao Gongzuodui 2000). According to the classics, in the year before his death, Wenwang, the father of Wuwang, moved the "capital" of the Zhou from Zhouyuan to Feng, as a strategy of eastward expansion and the final showdown with the Shang. ${ }^{3}$ A few years later Wuwang defeated Dixin at Muye (there are several versions of the number of years between the establishment of Feng and the conquest, varying from two to five). If the classical texts are accurate, the Zhou people started to reside at Feng no more than a decade before the conquest. A major site of about 6 $\mathrm{km}^{2}$ located on the west bank of the Feng River is regarded as the most likely archaeological candidate for the location of Feng. The site, now known as Fengxi, yields an uninterrupted sequence stretching from the proto-Zhou culture, i.e., the Zhou culture before the conquest, to the mid-Zhou culture. This site is regarded as particularly significant for the archaeological dating of the historical event of the Shang-Zhou transition.

In order to employ optimal radiocarbon sampling strategy for the high-precision ${ }^{14} \mathrm{C}$ dating and wiggle-matching procedures, new radiocarbon samples had to be collected in the field. The radiometric specialists worked together with the archaeologists in an early stage of the excavation to guarantee the collection of serial samples from a number of contexts, within a well-stratified sequence at least from the proto-Zhou to the early Zhou. With this sampling question in mind, the archaeology team excavated a well-stratified unit, 97SCMT1, in 1997. Diagnostic pottery assemblages from the proto-Zhou to the mid-Zhou cultures were yielded from different strata or features (Fig. 3). Unit T1 had four cultural strata (1-4) and several ash pits (H8, H11, H16, and H18) were identified. Ash pit H18, opened at the bottom of T1(4) or Stratum 4 of Unit T1, provided the almost ideal corpus of dating material. The pit itself was further divided into four 


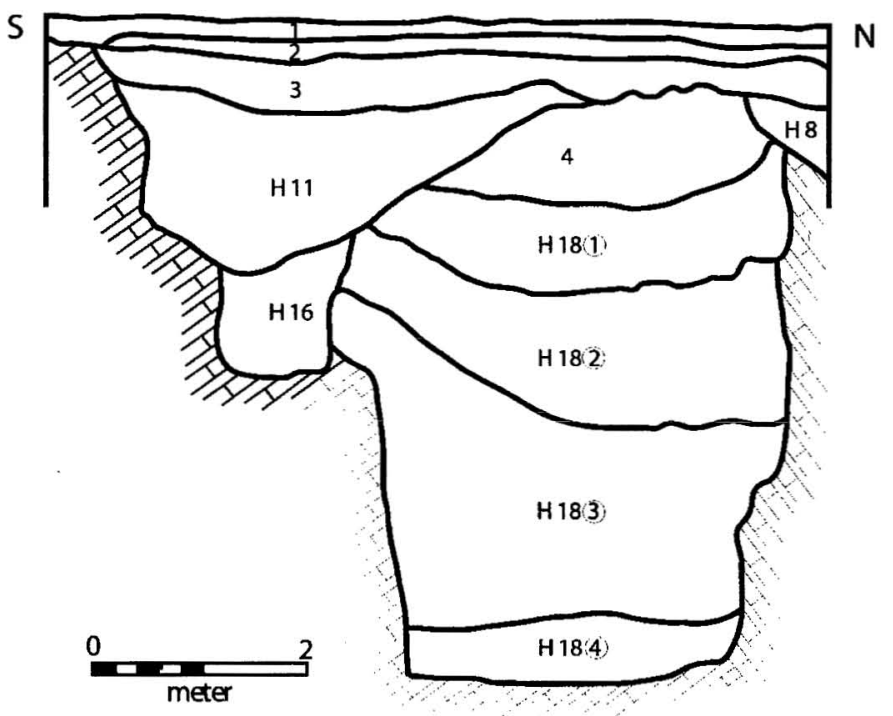

Fig. 3. Section of Fengxi unit 97SCMT1.

sublevels filled with diagnostic late proto-Zhou pottery sherds. The majority of T1(4), on the other hand, was ascribed to the incipient phase of early Zhou, that is to say a time period shortly after the conquest. Other features and strata superimposed or intruded into $\mathrm{H} 18$ and T1(4) were ascribed to that of the early Zhou (H16, H11) and the mid-Zhou (H8, T1[3]) cultures (Bulletin 30). Therefore, the conquest should have occurred within the date range of T1(4), some time between the upper limit of H18 and the lower limit of T1(4). For the sake of wiggle-matching, a series of radiocarbon samples were collected from the protoZhou to the mid-Zhou contexts. Most importantly, the stratified proto-Zhou remains of $\mathrm{H} 18$ were chronologically ordered. The ${ }^{14} \mathrm{C}$ dating was carried out both by conventional and AMS methods. After high-precision ${ }^{14} \mathrm{C}$ dating and wigglematching with the OxCal program, the conventional method yielded a conquest date bracketed between 1050 and 1010 B.C. The AMS method, because of higher margins of error, yielded the range 1060-995 B.C. (Xia-Shang-Zhou 2000:41).

Besides the dates extracted from the Fengxi site, long radiocarbon sequences were also collected from late Yinxu (late to terminal Shang), Liulihe (early Zhou), and Qucun (early Zhou) (Fig. 1). They are regarded as the archaeological corollaries of the different phases of the Shang-Zhou transition. When all the dates from different sites are considered simultaneously, they point to a conquest date between 1050 and 1020 B.C. (Xia-Shang-Zhou 2000:44). This result eliminates many of the propositions and shortens the possible conquest date from 112 years to 30 years.

The calendrical and astronomical records from the classics then help to pinpoint the exact date of the conquest within this span of thirty years. The classical text Wucheng is probably an address of the royal Zhou, and is a long-lost document. Nevertheless, 82 words of the passage are preserved in excerpts in the 
Hanshu (History of Han), which chronicle the conquest campaign in days, moon phases, and months (Ban 1962:1015-1016). Its authenticity is regarded as solid after testing against oracle and bronze inscriptions and other classics. The conquest date must therefore agree with this chronicle. Here I translate the related passages as follows:

In the first month (of the year), on the renchen day, the brightness of the moon has almost completely died out (pangsipo). On the following morning, that is the guisi day, King Wuwang started off the military campaign against Dixin from Zhou (probably Zhouyuan). Time had lapsed to the third month and five days after the dying brightness of the moon (jisipo). On the jiazi day, we killed the Shang King Dixin.

What a detailed time log we have in hand! We know the year, the month, the day, and the moon-phase notations associated with the conquest campaign. The conquest date must have to satisfy these conditions. Using an exhaustive permutation of the calendar (e.g., using different first months of the year), a set of ten different highly possible dates have been selected.

Another classical text, the Guoyu, contains a record of actual astronomical observation at the time when the conquest campaign was mounted:

Formerly, when King Wuwang attacked the Yin, Jupiter was in Quail Fire; the moon was in Heavenly Quadriga; the sun was in the Ford that separates Wood; the new moon was in the Handle of the [Southern] Dipper; Mercury was in the Heavenly Turtle.

By using a computer for astronomical retrocalculation, only one date satisfies the calendrical notations and the celestial phenomena between 1050 and 1020 в.C., which is 20 January 1046 в.C. (Xia-Shang-Zhou 2000:46-49).

In addition, we should not view the conquest as an isolated event. The conquest date should be placed among the other components of the Three Dynasties chronology, particularly the late Shang and early Western Zhou dates. The suggested conquest date integrates well with the independent studies of other dates, thus increasing its credibility.

Finally it is worth mentioning that the chronology project also includes two other propositions of the conquest date in the final report: 9 January 1044 B.C. and 1027 в.с. The chronology project intended to be inclusive. It followed different lines of reasoning to study the conquest date. It argues that the 1046 B.C. date fulfills most of the conditions and integrates well with the other components of the chronology project, while the other two dates do not. The key to the 1044 proposition is based on the controversial interpretation of a bronze inscription $\mathrm{Li}$ gui-vessel. The inscription contains one passage of seven graphs that has proven extremely obscure. Shaughnessy (1991:94) summarizes that there are eight different interpretations of this inscribed passage. If one of the interpretations advocated by Zhang Zhenglang- "Jupiter was upright and they were able at night to have Shang"-is subscribed to, it points to 1044 в.C. The 1027 в.C. proposition is primarily based on the historicity of a couple of dates in the classics. There is no doubt that Western Zhou terminated in 770 B.C., and the Guben Zhushu Jinian documents that the total regnal length of Western Zhou is 257 years (Fang and Wang 1981:61). Simple addition puts the conquest date at 1027 B.C. 


\section{CONCLUDING REMARKS}

At the commencement of the project, 200 experts had in hand from the literary history an incomplete and corrupted floating chronology, essentially calculated from a structure of regnal years for some kings and the total years for each of the Three Dynasties. The charge to this group of experts was to fix some datum points of absolute dates to anchor this floating chronology so that they could count backward and forward. After four and a half years of systematic and exhaustive investigation of the extant evidence, they have answered the challenge and have built to date the most comprehensive chronology table from the beginning of the Xia Dynasty to the end of the Western Zhou Dynasty. Because of the scarcity and inadequacy of chronological information, however, there are still problems and uncertainties in this chronology. It is anticipated that in the light of new data, the chronological table will be revised from time to time. As stressed by the committee of the chronology project at the outset, the result is a significant step closer toward the truth, but it is not in itself the ultimate truth (Bulletin 5). Li Xueqin also points out that the close of the project does not mean that the final goals have been reached; on the contrary, it indicates the beginning of a new era of chronological study of the Three Dynasties (Li Xueqin 1999:iii).

The chronologies of different time periods presented should be treated differently. There is obvious difference in the quantity and quality of the chronological data from the recent past to the remote past. For the later period spanning from late Shang to early Zhou, the chronology is fairly solid. It may be off only a few years for a given king, but there is not much room for manipulation. In contrast, the table gives a broad chronological framework for the Xia and early Shang periods simply because there are too many uncertain variables. At any rate, today we have a chronology of Chinese history that the school texts can adopt, though the debate among experts will continue.

A new round of debate among the experts might have already started. In a recent publication, Li Xueqin (1999:12-16) argues that the first year of the reign of King Yíwang of Western Zhou was 917 B.C. instead of 885 B.C. as designated in the project's chronology table. The difference stemmed from which king the Shanfu Shan ding-vessel should be assigned. The bronze vessel has a long inscription starting with: "During the thirty-seventh year of the king, in the first month, first auspiciousness (chuji), gengxu day,..." Li argues that the vessel should be assigned to King Yíwang, and the calendrical notations are consistent with 881 B.C. The first day of the first month of this particular year was the yisi day, and gengxu day was the sixth day of the month, which was within the lunar phase of chuji. The chronology project, on the other hand, ascribed this vessel to Liwang and the inscribed year (the 37 th year) was thus 841 B.C. (Xia-Shang-Zhou $2000: 23)$. This example is significant in several ways. It demonstrates that not every member of the chronology project agrees on all the dates. Regardless of the fact that Li Xueqin was the director of the project, this particular proposition was not accepted by the project. This is a healthy development in the Chinese academic community - that opinions are not taken because of the advocator's stature but are taken because of the merit of the opinion. Moreover, it implies that politics do not play a role in the specific details of the chronology project. 
The most precise chronological information coded in the written texts seems to be that of the astronomical events. With the help of a computer, retrocalculation of the positions of celestial bodies is available at just a touch of a finger. However, there is a dilemma in depending on the celestial rhythms for chronology building. Perhaps by the early second millennium B.c., the Chinese had firmly established a state of mind that there was a correlation between unusual astronomical observations and political events (Pankenier 1995). The most infrequent astronomical events are the most meaningful data for chronological study. Yet, they are also tempting subjects to be tampered with. Sometimes, there is no way of telling true astronomical observations from fabricated portents.

Chronology is one of the primary issues in the study of history and archaeology. Yet historical and archaeological dates are not completely compatible. Using archaeology to solve a question in historical chronology is inherently constrained. There are two specific problems here. The first problem is that archaeological dates are derived from radiocarbon procedures on materials collected in archaeological sites. A prerequisite for the value of radiocarbon dating in chronology building is then the accuracy of archaeological information. For instance, Feature $\mathrm{H} 18$ at Fengxi is the archaeological focus of the date of the Zhou conquest. How can we know for certain that the ${ }^{14} \mathrm{C}$ dates of $\mathrm{H} 18$ should correspond to the conquest date? The second problem is that although significant innovations have been made in the precision of radiocarbon dating, it still cannot reach the precision level that historians like to see. Using archaeology to build an absolute chronology is a matter of ranges rather than points in time. The margin of error of the radiocarbon dates can be minimized, but there is always a margin of error. Depending solely on ${ }^{14} \mathrm{C}$ dating and giving only a probability of a date within a range of twenty years would not make historians happy.

The paradigm of Chinese historical archaeology derives mainly from the written texts. The chronology project pushes it to the extreme. By emphasizing the chronology of the Three Dynasties, the project preserves the unilinear perspective of early Chinese civilization. Recent archaeological works indicate that there were other highly complex societies surrounding the Central Plains during the formative period of Chinese civilization. The rise of Chinese civilization was seemingly the result of the complex interaction of these different polities. That is exactly where archaeology can complement the documentary record. Instead, the archaeologists were charged by the chronology project to find features representing historical events, like the Zhou conquest. This is not a healthy trend for the study of the rise of Chinese civilization.

An interesting question is how have we improved our understanding of the chronology of ancient Chinese history? A good example for investigating this question is the argument that David Pankenier made in a 1981 paper wherein he maintained that King Wuwang defeated King Dixin at the Battle of Muye in 1046 B.C. (Pankenier 1981-82), exactly the same year as suggested by the chronology project. Pankenier reached this conclusion essentially based on the astronomical records in the classics. Although the chronology project reached the same conclusion by using some of the same data as Pankenier, it also exhaustively investigated all available information in archaeology, radiocarbon dating, the classics, and bronze and oracle inscriptions. The project also showed how this date integrates well with the other chronological elements of early Chinese civiliza- 
tion, and it becomes more convincing through the process. On the one hand, one cannot help admiring Pankenier's insight; while on the other hand one has to appreciate the power of interdisciplinary collaboration. Interdisciplinary collaboration is a rare practice in China. The chronology project has set a precedent for the future.

\section{ACKNOWLEDGMENTS}

There are a number of people to whom I am grateful. The inspiration for writing this paper came from the discussion with Cai Lienzhen, Li Boqin, Li Xueqin, Qiu Shihua, Yin Weizhang, Zhang Xuelian, and Zou Heng when they were presenting the Xia-Shang-Zhou Chronology Project at Harvard University. This paper has benefited from the thoughtful comments of Sarah Allan, Mark Byington, Chen Xingcan, David Cohen, Jiao Tianlong, Li Yung-ti, Niu Hung-jen, Shao Wangping, Yang Nan, Joshua Wright, Zhang Lidong, three anonymous reviewers, and the editor of Asian Perspectives. The discussion with David Nivison regarding the chronology project was stimulating. Sarah Allan provided me offprints of her papers. Yin Weizhang provided me a complete set of the bulletins and intriguing "insider" information. Mark Byington edited the first draft. Any remaining errors are my responsibility alone.

\section{NOTES}

1. The Bulletin of the Xia-Shang-Zhou Chronology Project is a newsletter sponsored by the Office of the Xia-Shang-Zhou Chronology Project. A total of slightly more than 100 volumes have been published since April 1996. Each volume consists of four pages of current news and discussions of the project. This paper quotes extensively from the bulletin. Only the volume number will be given for each quote.

2. The ganzhi system can be visualized as two interlocked cogwheels, one with ten and the other with twelve teeth, turning together day-by-day to produce a cycle of sixty ordered combinations (Chen Cheng-Yih and Xi 1993:44) (see Fig. 2). The first day of a cycle is the jiazi day; the second is the yichou day, and so on. When the tiangan completes one full cycle, it is called a $x u n$ or a ten-day week. The last day of the first xun is the guiyou day. Then it starts with the second xun of the cycle, with the first day as the jiaxu day.

3. Some argue, and I agree, that the Fengxi site looks more like a military camp than a center with administrative and ceremonial capacities (Hsu and Linduff 1988:92).

\section{REFERENCES CITED}

Allan, Sarah

1984 The myth of the Xia Dynasty. Journal of the Royal Asiatic Society 1984(2):242-256.

Allard, Francis

1998 Stirrings at the periphery: History, archaeology, and the study of Dian. International Journal of Historical Archaeology 2(4):321-341.

AN JiNHUAI

1961 Shilun Zhengzhou Shangdai chengzhi Aodu. Wenwu 1961(4, 5): 73-80.

1994 Henan Xiadai wenhua yanjiu yu zhanwang, in Henan Kaogu Sishi Nian: 423-439, ed. Henansheng Wenwu Yanjiusuo. Zhengzhou: Henan Renmin Press.

BAN Gu

1962 Hanshu. Beijing: Zhonghua Books.

Beijing Normal University, ed.

1997 Wuwang Ke Shang Zhi Nian Yanjiu. Beijing: Beijing Normal University Press.

BOWMAN, SHERIDAN

1990 Radiocarbon Dating. Berkeley: University of California Press. 
Buck, C. E., J. B. Kenworthy, C. D. Litton, And A.F.M. Smith

1991 Combining archaeological and radiocarbon information: A Bayesian approach to calibration. Antiquity 65:808-821.

Buck, C. E., C. D. Litton, And A.F.M. Smith

1992 Calibration of radiocarbon results pertaining to related archaeological events. Journal of Archaeological Science 19:497-512.

Cai Yunzhang, and Luo Fu

1988 Shangdu Xibo luelun. Huaxia Kaogu 1988(4):87-95, 37.

Chang, Kwang-Chin

1986 The Archaeology of Ancient China, 4th ed. New Haven: Yale University Press.

1989 Ancient China and its anthropological significance, in Archaeological Thought in America: 155-166, ed. Carl C. Lamberg-Karlovsky. Cambridge: Cambridge University Press.

Chen Cheng-Yih, and Xi Zezong

1993 The Yao Dian and the origins of astronomy in China, in Astronomies and Cultures: 32-66, ed. Clive L. N. Ruggles and Nicholas J. Saunders. Niwot: University Press of Colorado.

Chen Xingcan, And Liu Li

2001 Xia Shang Zhou Duandai Gongcheng yinqi de wang shang taolun jishi. Gudai Wenming Үапјіи 9:16-37.

Chen Xu

2000 Guanyu Yangshi Shangcheng he Zhengzhou Shangcheng de niandai wenti, in Xia Shang Wenhua Lunji: 119-128, ed. Chen Xu. Beijing: Kexue Press.

Christen, J. A., And C. D. Litton

1995 A Bayesian approach to wiggle-matching. Journal of Archaeological Science 22:719-725.

Dehling, Harold, and Johannes van der Plicht

1993 Statistical problems in calibrating radiocarbon dates. Radiocarbon 35(1): 239-244.

Diaz-Andreu, Margarita, and Timothy Champion

1996 Nationalism and archaeology in Europe: An introduction, in Nationalism and Archaeology in Europe: 1-23, ed. Margarita Diaz-Andreu and Timothy Champion. London: UCL Press.

Du, ZHENGZHENG

1990 Xia Wenhua keneng taolun ma? Xinshixue 1(2): 115-130.

ECKHOLM, ERIK

2000 In China, ancient history kindles modern doubts. The New York Times November 10.

FALKenHaUsen, Lothar von

1993 On the historiographical orientation of Chinese archaeology. Antiquity 67:839-849.

Fang Shiming, and Wang Xiuling

1981 Guben Zhushu Jinian Jizheng. Shanghai: Shanghai Guji Press.

Gao Wei, Yang Xizhang, Wang Wei, and Du Jinpeng

1999 Yanshi Shangcheng yu Xia Shang wenhua fenjie, in Sandai Wenmin Yanjiu (1): 186-199, ed. Zhongguo Yinshang Wenhua Xuehui et al. Beijing: Kexue Press.

Gilley, Bruce, ANd Zheng Zhou

2000 China: Nationalism. Digging into the future. Far Eastern Economic Review July 20.

Gu, JiEgANG

1982 Yu Qian Xuantong xiansheng lun gushishu, in Gushibian, vol. 1:59-66, ed. Gu Jiegang (reprint). Shanghai: Shanghai Guji Press.

Gu JiEgang, AND TONg SHUYe

1982 Xiashi san lun, in Gushibian, vol. 7(3):105-233, ed. Lü Simian and Tong Shuye (reprint). Shanghai: Shanghai Guji Press.

Hsu, Cho-yun, and Katheryn M. LindufF

1988 Western Chou Civilization. New Haven: Yale University Press.

JUNKER, LAURA L.

1998 Integrating history and archaeology in the study of contact period Philippine chiefdoms. International Journal of Historical Archaeology 2(4):291-320. 
Kametaro, TAKigawa

1974 Shiji Huizhu Kaozheng (reprint). Taipei: Hongye Books.

Keightley, David N.

1978 Sources of Shang History: The Oracle-Bone Inscriptions of Bronze Age China. Berkeley: University of California Press.

Kohl, Philip L., and Clare Fawcett

1995 Archaeology in the service of the state: theoretical considerations, in Nationalism, Politics, and the Practice of Archaeology: 3-18, ed. Philip L. Kohl and Clare Fawcett. Cambridge: Cambridge University Press.

Kojo, Yasushi, Robert M. Kalin, And Austin Long

1994 High-precision "wiggle-matching" in radiocarbon dating. Journal of Archaeological Science $21: 475-479$.

LI CHI

1977 Anyang. Seattle: University of Washington Press.

Li ENwei, Li Jun, AND SHI Congzhi

1999 Xingtai diqu Shang wenming chulun, in Sandai Wenmin Yanjiu (1): 45-50, ed. Zhongguo Yinshang Wenhua Xuehui et al. Beijing: Kexue Press.

Li XUEQIN

1997 Zouchu Yigu Shidai, 2nd ed. Shenyang: Liaoning University Press.

1999 Xia Shang Zhou Niandaixue Zhaji. Shengyang: Liaoning University Press.

Meskell, LyNN

1998 Introduction: Archaeology matters, in Archaeology Under Fire: 1-12, ed. Lynn Meskell. London: Routledge.

Orton, Clive

1980 Mathematics in Archaeology. London: Collins.

ÖZdô̂An, Mehmet

1998 Ideology and archaeology in Turkey, in Archaeology Under Fire: 111-123, ed. Lynn Meskell. London: Routledge.

Pankenier, David W.

1981- Astronomical dates in Shang and Western Zhou. Early China 7:1-37.

1982

1995 The cosmo-political background of heaven's mandate. Early China 20:121-176.

Pearson, G. W.

1986 Precise calendrical dating of known growth-period samples using a 'curve-fitting' technique. Radiocarbon 28(2A) : 292-299.

Peng Jinzhang, and Xiao Tian

1988 Yinxu wei Wuding yilai Yin zhi jiudu shuo, Zhongguo Kaogu Xuehui Diwuci Nianhui Lunwenji: 17-23, ed. Zhongguo Kaogu Xuehui. Beijing: Wenwu Press.

Qiu Shinua, AND Cai Lianzhen

1997 Tan shisi duandai jishu de xing jinzhan yu Xia Shang Zhou duandai gongcheng. Kaogu 1997(7): 1-4.

1998 Jiejue Shang Zhou jinian wenti de yixian xiwang, in Zhongguo Shang Wenhua Guoji Xueshu Taolunhui Lunwenji: 442-449, ed. Zhongguo Shehui Kexueyuan Kaogu Yanjiusuo. Beijing: Zhongguo Dabaike Quanshu Press.

Ramsey, Christopher B.

1994 Analysis of chronological information and radiocarbon calibration: The program OxCal. Archaeological Computing Newsletter 41:11-16.

1995 Radiocarbon calibration and analysis of stratigraphy: The OxCal program. Radiocarbon 37(2): 425-430.

1998 Probability and dating. Radiocarbon 40(1):461-474.

Shaughnessy, EDWARD L.

1991 Sources of Western Zhou History: Inscribed Bronze Vessels. Berkeley: University of California Press.

SONG JIAN

1999 Chaoyue Yigu Zouchu Mimang: Huhuan Xia Shang Zhou Duandai Gongcheng. Shanghai: Shanghai Keji Jiaoyu Press. 
Stark, Miriam T., and S. Jane Allen

1998 The transition to history in Southeast Asia: An introduction. International Journal of Historical Archaeology 2(3) : 163-174.

Storey, GLenn R.

1999 Archaeology and Roman society: Integrating textual and archaeological data. Journal of Archaeological Research 7(3): 203-248.

Stuiver, Minze, and Gordon W. Pearson

1986 High-precision calibration of the radiocarbon time scale, A.D. 1950-500 B.C. Radiocarbon 28(2B) : 805-838.

Stuiver, Minze, Paul J. Reimer, Edouard Bard, J. Warren Beck, G. S. Burr, Konrad A. Hughen, Bernd Kromer, Gerry McCormac, Johannes van der Plicht, and Marco Spurk 1998 INTCAL98 radiocarbon age calibration, 24,000-0 cal BP. Radiocarbon 40(3): 1041-1083.

\section{SU BINGQI}

1999 Zhongguo Wenming Qiyuan Xintan. Beijing: Sanlian Press.

Sun Hua

1980 Guanyu Erlitou wenhua. Kaogu 1980(6):521-525.

1999 Shang wenhua yanjiu de ruogan wenti, in Sandai Wenmin Yanjiu (1): 345-359, ed. Zhongguo Yinshang Wenhua Xuehui et al. Beijing: Kexue Press.

TANG JIGEN

1993 Yinxu yiqi wenhua ji qi xiangguan wenti. Kaogu 1993(10) :925-935.

TANG Jigen, And Xu GuAngde

1999 Huanbei Huayuanzhuang yizhi yu Pangeng qian Yin wenti. Zhongguo Wenwu Bao, April 14, 1999.

THORP, ROBERT L.

1991 Erlitou and the search for the Xia. Early China 16:1-38.

Thurston, Tina L.

1997 Historians, prehistorians, and the tyranny of the historical record: Danish state formation through documents and archaeological data. Journal of Archaeological Method and Theory $4: 239-263$.

TONG, ENZHENG

1995 Thirty years of Chinese archaeology (1949-1979), in Nationalism, Politics, and the Practice of Archaeology: 177-197, ed. Philip L. Kohl and Clare Fawcett. Cambridge: Cambridge University Press.

Trigger, Bruce G.

1995 Romanticism, nationalism, and archaeology, in Nationalism, Politics, and the Practice of Archaeology: 263-279, ed. Philip L. Kohl and Clare Fawcett. Cambridge: Cambridge University Press.

Vogel, J. C., Annemarie Fuls, Ebbie Visser, and Bernd Becker

1986 Radiocarbon fluctuations during the third millennium B.C. Radiocarbon 28(2B) : 935-938.

WANG WEI

2000 Xia Shang Zhou kaoguxue de huigu yu zhanwang, in Zhongguo Kaoguxue Kua Shiji de Huigu yu Qianzhan: 63-83, ed. Zhang Zhongpei and Xu Zuoyun. Beijing: Kexue Press.

WANG XUERONG

1997 Henan Yanshi Shangcheng yizhi de kaogu fajue yu yanjiu shuping, in Kaogu Qiuzhiji: 286-307, ed. Zhongguo Shehui Kexueyuan Kaogu Yanjiusuo. Beijing: Zhongguo Shehui Kexue Press.

WANG YUZHE

2000 Zhonghua Yuangu Shi. Shanghai: Shanghai Renmin Press.

WANG ZHONGSHU

1984 Chuban Shuming, in Yin Zhou Jingwen Jicheng, vol. 1:9-11, ed. Kaogu Yanjiusuo. Shanghai: Zhonghua Books.

WEN YU

1999 Huanbei Huayuanzhuang yizhi yu Hetanjia ju Xiang. Zhongguo Wenwu Bao, November 25,1998 
WRIGHT, HENRY T.

1998 Developing complex societies in Southeast Asia: Using archaeological and historical evidence. International Journal of Historical Archaeology 2(4):343-348.

Xia-Shang-Zhou Chronology Project Zhuanzu

2000 Xia-Shang-Zhou Duandai Gongcheng 1996-2000 Nian Jieduan Chengguo Baogao, Jianben. Beijing: Shijie Tushu Publishing Company.

Xu Xusheng

19591959 nian xiaYuxi diaocha 'Xiaxu' de chubu baogao. Kaogu 1959(11):592-600

YANG XIZHANG

1981 Anyang Yinxu Xibeigang damu de fenqi ji youguan wenti. Zhongyuan Wenwu 1981(3): 47-52.

YIN WEIZHANG

1978 Erlitou wenhua tantao. Kaogu 1978(1): 1-4.

ZHENG GUANG

1988 Erlitou yizhi de xingzhi he niandai. Kaogu yu Wenwu 1988(1):18-25.

Zhongguo Kexueyuan Kaogu Yanjiusuo Luoyang Fajuedui

1961 Yijiuwujiu nian Henan Yanshi Erlitou shijue jianbao. Kaogu 1961(2):28-85.

1965 Henan Yanshi Erlitou yizhi fajue jianbao. Kaogu 1965(5):215-224.

Zhongguo Shehui Kexueyuan Kaogu Yanjiusuo

1980 Yinxu Fuhao Mu. Beijing: Wenwu Press.

1994 Yinxu de Faxian yu Yanjiu. Beijing: Kexue Press.

1999 Yanshi Erlitou. Beijing: Zhongguo Dabaike Quanshu Press.

Zhongguo Shehui Kexueyuan Kaogu Yanjiusuo Anyang Gongzuodui

1998 Henan Anyangshi Huanbei Huayuanzhuang yizhi 1997 nian fajue jianbao. Kaogu $1998(10): 23-35$.

Zhongguo Shehui Kexueyuan Kaogu Yanjiusuo Erlitou Gongzuodui

1974 Henan Yanshi Erlitou zaoshang gongdian yizhi fajue jianbao. Kaogu 1974(4): 234-248.

Zhongguo Shehur Kexueyuan Kaogu Yanjiusuo Fenghao Gongzuodui

2000 Yijiujiuqi nian Fengxi fajue baogao. Kaogu Xuebao 2000(2):99-245.

Zhongguo Shehui Kexueyuan Kaogu Yanjiusuo Henan Dier Gongzuodui

1984 Yijiubasan nian qiu Henan Yanshi Shangcheng fajue jianbao. Kaogu 1984(10): 872-879.

1988 Henan Yanshi Shixianggou Shangcheng diwu gongdian jizhi fajue jianbao. Kaogu 1988(2): 128-140.

1998 Henan Yanshi Shangcheng dongbeiyu fajue jianbao. Kaogu 1998(6):1-8.

1999 Henan Yanshi Shangcheng xiaocheng fajue jianbao. Kaogu 1999(2):1-11.

Zhongguo Shehui Kexueyuan Kaogu Yanjiusuo Luoyang Han Wei Gucheng Gongzuodui 1984 Yanshi Shangcheng de chubu kantan he fajue. Kaogu 1984(6): 488-504, 509.

Zou Heng

1979 Guanyu tantao Xia wenhua de jige wenti. Wenwu 1979(3):64-69.

1998a Xia Shang Zhou Kaoguxue Lunwenji (Xuji): 120-122, ed. Zou Heng. Beijing: Kexue Press.

$1998 b$ Yanshi Shangcheng ji Taijia Tonggong shuo, in Xia Shang Zhou Kaoguxue Lunwenji (Xuji): 120-122, ed. Zou Heng. Beijing: Kexue Press.

\section{ABSTRACT}

The generally accepted chronology of Chinese history begins in 841 B.C., seventy years before the end of the Western Zhou Dynasty. In Shiji, Sima Qian (c. 14589 B.C.) compiled a chronological table of twelve contemporary states starting with 841 B.C. Over the past two thousand years, scholars have tried to extend the dates farther back, but without agreement. The Xia-Shang-Zhou Chronology Project was recently commissioned by the Chinese Government to systematically reconstruct a reliable chronology of early Chinese history starting with the Xia Dynasty. After almost five years and the efforts of some 200 experts in different fields of study, a new chronological table of early China was disseminated in November 
2000. It was anticipated that all future discussions on the absolute dates of early China would have to be based on the project's results. This paper discusses the main debates stimulated by the project and critically evaluates the methodology it employed. As a well-informed observer of the project, the author becomes aware of a number of intriguing issues regarding the study of the past in China, such as politics and the reconstruction of the past, the relationship between the archaeological record and the documentary record, and the compatibility of archaeological dates and historical dates. A discussion of these issues has broad implications for archaeology in other parts of the world. Keywords: China, dates, Three Dynasties, palaeography, high-precision dating. 